\title{
Improved Dissolution Rate of Piroxicam by Fusion Solid Dispersion Technique
}

\author{
Manohara $C^{1^{\star}}$, Jagadeesh S. Sanganal ${ }^{1}$, Prem Kumar ${ }^{1}{ }^{1}$, Swamy KB ${ }^{1}$, Phani $A^{2}$ \\ ${ }^{1}$ Department of Pharmacology and Toxicology, Veterinary College, Bangalore, Karnataka, India \\ ${ }^{2}$ Nano-RAM Technologies, Bangalore, Karnataka, India
}

\begin{tabular}{|c|c|}
\hline Abstract & Article Information \\
\hline \multirow{9}{*}{$\begin{array}{l}\text { Improving oral bioavailability of drugs those given as solid dosage forms remains a } \\
\text { challenge for the formulation scientists due to solubility problems. The dissolution rate } \\
\text { could be the rate-limiting process in the absorption of a drug from a solid dosage form of } \\
\text { relatively insoluble drugs. Therefore increase in dissolution of poorly soluble drugs by } \\
\text { solid dispersion technique presents a challenge to the formulation scientists. In the } \\
\text { present work solid dispersed drug was prepared by Fusion technique as a novel system } \\
\text { for enhancing the delivery of piroxicam, a non-steroidal anti-inflammatory drug. This solid } \\
\text { dispersed drug was prepared from polyvinyl pyrrolidone (PVP) (pharmaceutical grade), a } \\
\text { biodegradable polymer, to obtain a solution with drug: polymer ratio of } 1: 5 \text {. The release } \\
\text { rate of the piroxicam solid dispersed drug was studied in simulated gastric fluid. Fourier } \\
\text { transform infrared (FTIR) and scanning electron microscopy (SEM) are used to evaluate } \\
\text { the chemical and physical nature. The results showed that the release rates were twice } \\
\text { increased in comparison with the pure drug. However, the blend of drug and polymer } \\
\text { could be varied to optimize the release rates depending upon the need and formulation. } \\
\text { Copyright@2014 STAR Journal. All Rights Reserved. }\end{array}$} & $\begin{array}{l}\text { Article History: } \\
\text { Received : } 15-01-2014\end{array}$ \\
\hline & Revised : 17-03-2014 \\
\hline & Accepted : 22-03-2014 \\
\hline & $\begin{array}{l}\text { Keywords: } \\
\text { Piroxicam }\end{array}$ \\
\hline & Solid dispersed drug \\
\hline & Scanning electron microscopy \\
\hline & Dissolution rate \\
\hline & $\begin{array}{l}\text { *Corresponding Author: } \\
\text { Manohara C }\end{array}$ \\
\hline & \\
\hline
\end{tabular}

\section{INTRODUCTION}

Oral bioavailability of drugs depends on its solubility and/or dissolution rate, the major problem associated with poorly-water soluble drugs was its very low solubility in biological fluids, which results into poor bioavailability after oral administration (Sekiguchi, and Obi, 1961; Leunner, and Dressman, 2000). A drug with poor aqueous solubility will typically exhibit dissolution rate limited absorption, and a drug with poor membrane permeability will typically exhibit permeation rate limited absorption (Goldberg et al., 1966). Therefore, pharmaceutical researchers' focuses on two areas for improving the oral bioavailability of drugs include: (i) enhancing solubility and dissolution rate of poorly water-soluble drugs and (ii) enhancing permeability of poorly permeable drugs (Amidon et al., 1995).

Piroxicam is a member of the oxicam group of nonsteroidal anti-inflammatory drugs (NSAIDs). The chemical name for piroxicam is 4-hydroxyl-2-methyl-N-2-pyridinyl-2 $\mathrm{H}-1$, 2- benzothiazine-3-carboxamide 1,1-dioxide. It is indicated for acute or long-term use in the relief of signs and symptoms of osteoarthritis and rheumatoid arthritis (Physicians' Desk reference, $56^{\text {th }}$ ed, 2002). According to the Biopharmaceutic Drug Classification System (BCS) (Amidon et al., 1995) piroxicam is a class 2 drug, characterized by low solubility-high permeability. Drug dissolution in vivo is the rate-controlling step in drug absorption. Several techniques have been used to improve the oral bioavailability of piroxicam by accelerating its dissolution rate. These mainly include the solid dispersion techniques based on cyclodextrin inclusion complexes (Reddy and udupa 1993; Cavallari et al., 2002), polyvinyl pyrrolidone (Tantishaiyakul et al., 1999), polyethylene glycols 4000 and 6000 (Bhattacharyya et al., 1993; Fernandez et al., 1992).

Solid dispersions technique have tremendous potential for improving drug solubility due to the following factors (Leuner and Dressman, 2000; Damian et al., 2000; Govindasamy et al., 2013): a reduction of drug's particle size to nearly a molecular level, a solubilising or a cosolvent effect on the drug by the water soluble carrier, better wettability and dispersibility of the drug by the carrier material, and the formation of amorphous forms of drug and carriers. Polymerization of vinyl pyrrolidone leads to polyvinyl pyrrolidone (PVP) of molecular weights ranging from 2500 to $3,000,000$. These can be classified according to the $\mathrm{K}$ value (Walking 1994). Due to their good solubility in a wide variety of organic solvents, they are particularly suitable for the preparation of solid dispersions by the solvent method. Similarly to the PEGs, PVPs have good water solubility and can improve the wettability of the dispersed compound in many cases. Improved wetting and thereby an improved dissolution rate from a solid dispersion in PVP has been demonstrated for flufenamic acid (Aso et al., 2009). The chain length of the PVP has a very significant influence on the dissolution rate of the dispersed drug from the solid dispersion. The aqueous solubility of the PVPs becomes poorer and viscosity lowers with increasing chain length. 
Manohara et alo,

PVP as excipients has been studied extensively for increasing solubility and enhancing intestinal permeability and oral bioavailability of poorly water soluble drugs (Damian et al., 2000; Itoh et al., 2002). The present study was designed to improve the dissolution rate of piroxicam at the physiological pH's through its increased solubility by preparing semi-solid dispersions of the drug with polyvinyl pyrrolidone (PVP). The effect of PVP as excipients on the solubility and dissolution rate of piroxicam was evaluated. FTIR analysis between drug and polymer was performed to investigate possible interactions between drug and excipients.

\section{MATERIALS AND METHODS}

\section{Materials}

Piroxicam ( $\geq 98.0 \%)$, Polyvinyl Pyrrolidine (PVP) $(\mathrm{Mw}=13,00,000)$ and Dialysis tubing cellulose membrane have been purchased from Sigma-Aldrich, Bangalore, India. Ethanol, Monobasic sodium phosphate $\left(\mathrm{NaH}_{2} \mathrm{PO}_{4}\right)$ and dibasic sodium phosphate $\left(\mathrm{Na}_{2} \mathrm{HPO}_{4}\right)$ were purchased from Emplura ${ }^{\circledR}$, Merck Specialities Private Limited, Bangalore, India.

Preparation of Piroxicam Based Solid Dispersed Drug

Piroxicam based solid dispersed drug was prepared by Fusion/ Melt technique (Sekiguchi, and Obi, 1961). 150 $\mathrm{mg}$ Piroxicam drug was dissolved in $10 \mathrm{ml}$ of $0.75 \%$ of PVP polymer containing heated ethanol by continuous stirring, giving the drug and polymer concentration ratio of 1: 5 (Piroxicam : PVP). After complete dissolving of Piroxicam drug, drug polymer solution was transferred to the mortar and allowed it to cool under room temperature. After complete cooling and solidification of drug polymer solution in mortar it was finely churned to powder by using passel giving Piroxicam based PVP solid dispersed drug.

\section{Characterization of Solid Dispersed Drug}

\section{SEM Analysis}

The external surface morphology and diameter of Piroxicam based PVP solid dispersed drug were studied by SEM. The solid dispersed drug was observed under a scanning electron microscope (FEI Quanta 200, Indian Institute of Science, Bangalore). They were mounted directly on to the SEM sample stub using double-sided sticking tape and coated with gold film (thickness $200 \mathrm{~nm}$ ) under reduced pressure $\left(10^{-4} \mathrm{~mm}\right.$ of $\left.\mathrm{Hg}\right)$.

\section{FTIR Analysis}

The procedure involving sample preparation and spectral recordings was carried out by previously described method (Stuart et al., 2004). IR spectra of Piroxicam, PVP and PVP solid dispersed drug were recorded using FTIR Nicolet 6700 (Thermo Fisher Scientific, Madisson, WI, USA) operated by Omnic software 8.1. In particular, for oral thin films measurement the spectra were obtained by attenuated total reflectance (ATR) method using smart orbit diamond ATR. Briefly, the formulations were placed individually on the sample plate of the smart orbit and screwed lightly to record IR spectra in ATR mode.

\section{In vitro Dissolution Studies \\ Construction of Calibration Curve}

Piroxicam can be estimated spectrophotometrically at $\lambda_{\max } 330 \mathrm{~nm} .100 \mathrm{mg}$ of piroxicam was dissolved in $0.1 \mathrm{~N}$ methanolic $\mathrm{HCl}$ to obtain a solution with the piroxicam concentration of $100 \mu \mathrm{g} \mathrm{ml}^{-1}$. Serial dilutions containing 2, $4,6,8,10 \mathrm{~g} \mathrm{ml}^{-1}$ of piroxicam were prepared with the
Sci. Technol. Arts Res. J., Jan-March 2014, 3(1): 44-47

same solvent. Absorbance of each solution was measured at $333 \mathrm{~nm}$. A plot of concentrations of drug versus absorbance was plotted (Figure 1).

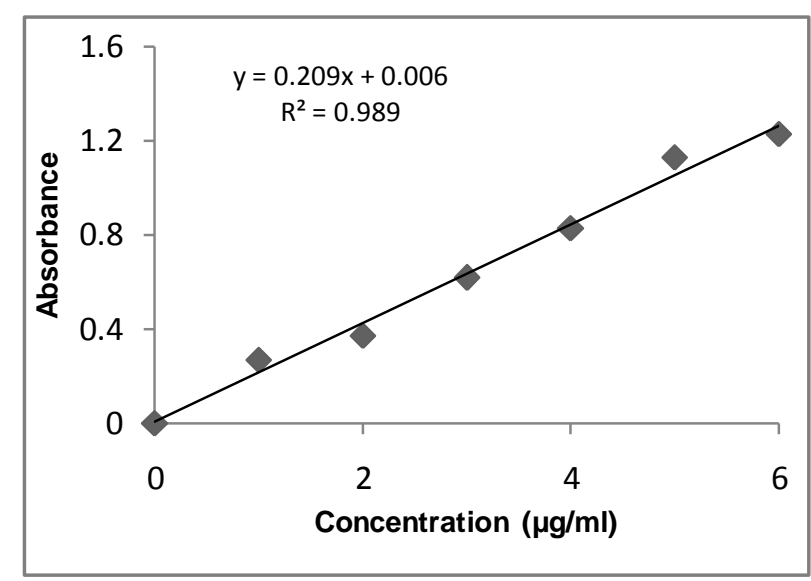

Figure 1: Calibration curve for the estimation of piroxicam in $0.1 \mathrm{~N}$ methanolic $\mathrm{Hcl}$ at $333 \mathrm{~nm}$.

\section{Estimation of Piroxicam Concentration}

Piroxicam based PVP solid dispersed drug equivalent to $20 \mathrm{mg}$ of piroxicam were weighed and dissolved in 0.1 $\mathrm{N}$ methanolic $\mathrm{HCl}$ and the absorbance was measured at $333 \mathrm{~nm}$.

\section{In vitro Release Behavior of Piroxicam}

The in vitro dissolution studies were done to compare the rate of dissolution of these prepared Piroxicam based PVP solid dispersed drug with that of the pure drug. The test was performed in the United States Pharmacopeia Convention USP paddle apparatus using $900 \mathrm{ml}$ of $0.1 \mathrm{~N}$ $\mathrm{HCl}\left(\mathrm{pH} \mathrm{1.2)}\right.$ at $37 \pm 0.5^{\circ} \mathrm{C}$ and $50 \mathrm{rpm}$. Aquilots of $5 \mathrm{ml}$ were withdrawn at various time intervals of $5,10,20,30$ and $60 \mathrm{~min}$ and analyzed by UV spectrophotometer (Evolution 300; Thermo Fisher Scientific, Madisson, WI, USA) at $333 \mathrm{~nm}$.

\section{RESULTS AND DISCUSSION}

\section{Physico-Chemical Characterization}

\section{SEM Analysis}

The solid dispersed drug was observed under a scanning electron microscope (FEI Quanta 200, Indian Institute of Science, Bangalore). Solid dispersed drug obtained was with average diameter of about $3600 \mathrm{~nm}$ (Image $\mathrm{J}$ software, provided by National Institutes of Health, USA). Piroxicam solid dispersed drug was detected by electron microscopy, indicating uniform distribution of drug and polymer solution (Figure-2a \& $2 b$ ). The Piroxicam-PVP loaded solid dispersed drug diameter is large and can be decreased by further optimizing the parameters used for the fusion/melt process.

\section{FTIR Analysis}

IR spectra of piroxicam and Polyviny pyrrolidone were shows the prominent peeks for functional group like $\mathrm{N}-\mathrm{H}$, $\mathrm{C}-\mathrm{H}$ (aliphatic and aromatic), $\mathrm{C}=\mathrm{O}, \mathrm{C}-\mathrm{O}, \mathrm{C}-\mathrm{N}, \mathrm{C}-\mathrm{F}$ and $\mathrm{S}=\mathrm{O}$. When comparing the solid dispersed piroxicam with Polyviny pyrrolidone, have found no interaction of piroxicam with Polyviny pyrrolidone, which are confirmed with the prominent peeks of functional groups and does not show any additional peeks for other functional groups (Figure 3 and Table 1). 


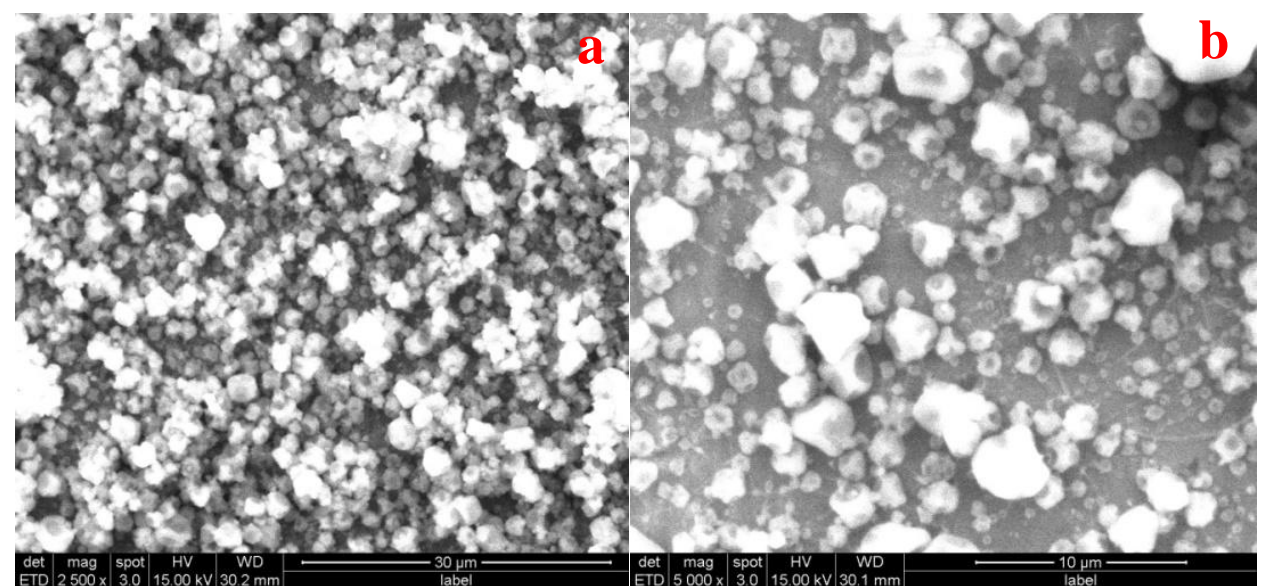

Figure 2: SEM images of Piroxicam-PVP solid dispersed drug a) Lower magnification b) Higher magnification.

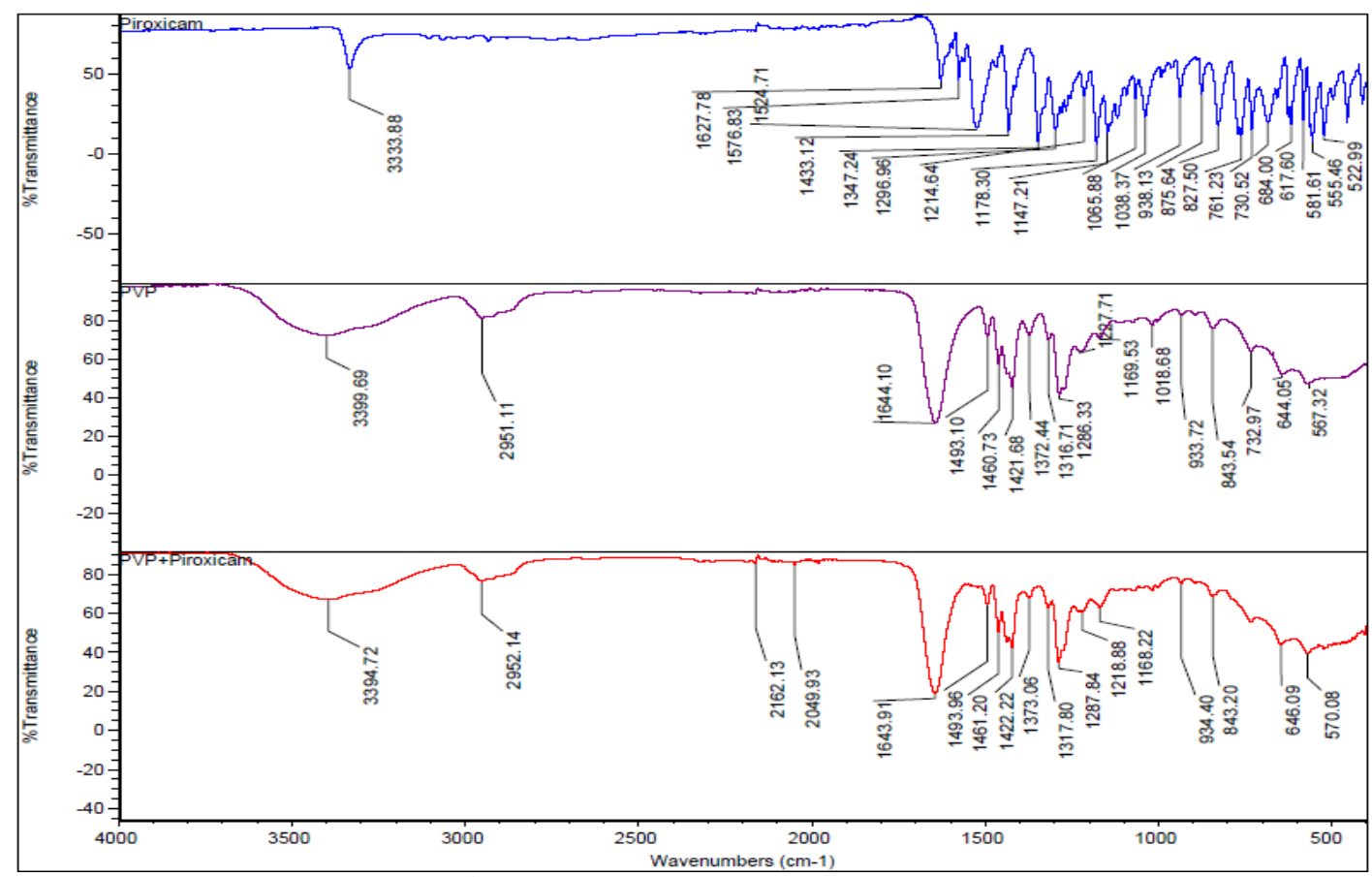

Figure 3: FTIR spectra of Piroxicam, PVP and Piroxicam solid dispersion with PVP.

Table 1: FTIR assignments of free and entrapped Piroxicam in PVP.

\begin{tabular}{ccc}
\hline \multirow{2}{*}{$\begin{array}{c}\text { Fundamental } \\
\text { Vibrations }\end{array}$} & Piroxicam & \begin{tabular}{c} 
Wave number (cm-1) \\
\cline { 2 - 3 } Piroxicam: \\
PVP solid dispersed drug
\end{tabular} \\
\hline N-H (stretch) & 3333.88 & 3394.72 \\
C-H(stretch) & 3010.2 & 2952.14 \\
C=O & 1627.78 & 1643.91 \\
C-O & 1214.64 & 1287.84 \\
C=C & 1433.12 & 1461.20 \\
C-N & 1347.24 & 1373.06 \\
S=O & 1038.37 & 1050.02 \\
C-F & & 1422.22 \\
\hline
\end{tabular}

\section{In vitro Dissolution Studies}

The rate of piroxicam released from Piroxicam based PVP solid dispersed drug was studied at $\mathrm{pH} 1.2$ and at temperature of $37 \pm 0.5^{\circ} \mathrm{C}$. The rate of release of piroxicam from solid drug is governed by temperature, nature of the used polymer and $\mathrm{pH}$ of the used simulated fluid. The solid dispersion technique is newly utilized in the field of drug delivery. It provides a unique and simple technique for improving drug delivery. The advantages of this technique are that it could be applied for a wide range of pharmaceutical compounds depending upon their nature. It could be applied for a mixture of drugs at the same time; besides, polymer blends could be used as solid dispersed drug at the same time. Also, it is possible to mix different polymeric drug molecules as layers which will help in layer-by-layer assembly to enhance the dissolution rate. The release rate of piroxicam based PVP solid dispersed drug showed a relatively higher rate than that of pure drug (Table 2 and Figure 4). After 60 min of dissolution time there is a marked increase in dissolution rate from $71.47 \pm$ 0.81 to $94.32 \pm 0.59$ which clearly indicates that around $91 \%$ of the drug concentration is available with solid dispersed drug and only $63 \%$ for pure drug. 
Manohara et al.,

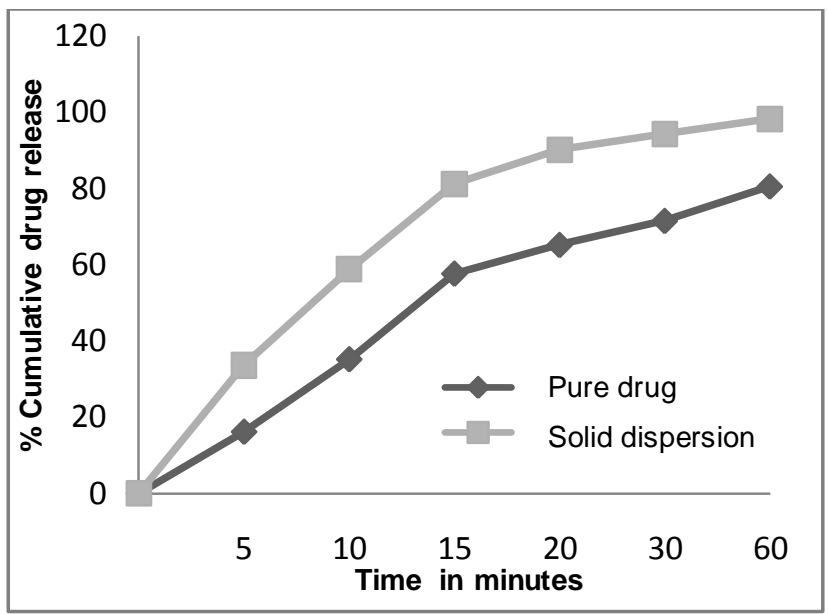

Figure 4: Comparative dissolution profile of Solid dispersed Drug and pure drug in $0.1 \mathrm{~N} \mathrm{HCl}$.

Table 2: Comparative dissolution profile of Solid dispersed Drug and pure drug at $\mathrm{pH} 1.2$.

\begin{tabular}{ccc}
\hline Time (min) & \multicolumn{2}{c}{ Cumulative \% of drug dissolved } \\
\cline { 2 - 3 } & $\begin{array}{c}\text { Piroxicam pure } \\
\text { drug }\end{array}$ & $\begin{array}{c}\text { Piroxixam: PVP (1:5) } \\
\text { solid dispersed drug }\end{array}$ \\
\hline 5 & $16.12 \pm 0.33$ & $33.58 \pm 0.46$ \\
10 & $35.17 \pm 0.72$ & $58.81 \pm 0.72$ \\
20 & $57.63 \pm 0.87$ & $81.15 \pm 0.53$ \\
30 & $65.16 \pm 0.53$ & $90.22 \pm 0.92$ \\
60 & $71.47 \pm 0.81$ & $94.32 \pm 0.59$ \\
\hline
\end{tabular}

\section{CONCLUSION}

In the present study PVP was employed in the preparation of solid dispersed drug, as it acts as a hydrophilic carrier, thereby enhancing the dissolution rate of the drug. The release rate of Piroxicam-PVP solid dispersed drug dissolution was twice increased as compared with the pure drug. SEM analysis indicated the average diameter of PVP solid dispersed drug (3600 nm). FTIR spectra indicated the absence of drug-polymer interactions. A new drug delivery system for piroxicam, a non-steroidal anti-inflammatory drug (NSAID), was developed. These systems were based on fusion $\mathrm{method} / \mathrm{melt}$ method of piroxicam with a suitable polymer. PVP polymer is biodegradable and biocompatible. Further research will be focused on optimization of parameters like $\mathrm{pH}$, temperature and drug: polymer ratio etc to control the release and structure of these drug polymer solid dispersed drugs.

\section{ACKNOWLEDGMENTS}

The authors are grateful to the management of the Department of Pharmacology and Toxicology, Veterinary College, Bangalore, Karnataka State, India and NanoRAM Technologies, Bangalore, Karnataka State, India for their financial support in carrying out this investigation.

\section{REFERENCES}

Amidon, G.L., Lennernas, H., Shah, V.P., Crison, J.R. (1995). A theoretical basis for biopharmaceutical drug classification: The correlation of in vitro drug product dissolution and in vivo bioavailability. Pharmaceutical Research 12(3): 413-420.
Sci. Technol. Arts Res. J., Jan-March 2014, 3(1): 44-47

Aso, Y., Miyazaki, T., Yoshika, S., Kawanishi, T. (2009). Molecular mobility of flufenamic acid in solid dispersions as determined by 19 F-NMR relaxation time. AAPS Pharm SciTech 11:S2.

Bhattacharyya, M., Basu, S.K., Gupta, B.K., Ghosal, S.K., Mandal, S.C., Chattaraj, S.C. (1993). Formulation and in vitro-in vivo characterization of solid dispersions of piroxicam. Drug Development and Industrial Pharmacy 19: $29-35$

Cavallari, C., Abertini, B., González-Rodríguez, M.L., Rodrıguez, L. (2002). Improved dissolution behaviour of steam-granulated piroxicam. European Journal of Pharmaceutics and Biopharmaceutics 54: 65-73.

Damian, F., Blaton, N., Naesens, L., Balzarini, J., Kinget, R., Augustijns, P., Van Den Mooter, G. (2000). Physicochemical characterization of solid dispersions of the antiviral agent UC-781 with polyethylene glycol 6000 and Gelucire 44/14. European Journal of Pharmaceutics and Biopharmaceutics 10: 311-322.

Fernández, M., Rodrígue, I.C., Crezo, A. (1992). Characterization of solid dispersions of piroxicam/ polyethylene glycol 4000. International Journal of Pharmaceutics 84: 197-202.

Goldberg, A.H., Gibaldi, M., Kanig, J.L. (1966). Increasing dissolution rates and gastrointestinal absorption of drugs via solid solutions and eutectic mixtures II. Experimental evaluation of eutectic mixture: Urea-acetaminophen system. Journal of Pharmaceutical Sciences 55(5): 482487.

Govindasamy, T., Vidya, S., Vinola, J. S., Jayasudha, Babu, V., Selvasundhari, L, Sivakami, R., Anthoni, S. A. (2013). Antimicrobial activity of Silver Nanoparticles synthesized by Marine Lactobacillus Sp. against Multiple Drug Resistance Pathogens. Science, Technology and Arts Research Journal 2(4): 05-09.

Itoh, K., Tozuka, Y., Oguchi, T., Yamamoto, K. (2002). Improvement of physicochemical properties of $\mathrm{N}-4472$ part I formulation design by using self-microemulsifying system. International Journal of Pharmaceutics 28: 153160.

Leuner, C., Dressman, J. (2000). Improving drug solubility for oral delivery using solid dispersions. European Journal of Pharmaceutics and Biopharmaceutics 50(1): 47-60.

Physicians' Desk reference, $56^{\text {th }}$ ed, (2002). Medical Economics Company, Inc, Montvale, NJ: 2685.

Reddy, D.N., Udupa, N. (1993). Formulation and evaluation of oral and trans- dermal preparations of flurbiprofen and piroxicam incorporated with different carriers. Drug Development and Industrial Pharmacy 19: 843-852.

Sekiguchi, K., Obi, N. (1961). Studies on absorption of eutectic mixture. A comparison of the behavior of eutectic mixture of sulfathiazole and that of ordinary sulfathiazole in man. Chemical and Pharmaceutical Bulletin 9: 866872.

Tantishaiyakul, V., Kaewnopparat, N., Ingkatawornwong, S. (1999). Properties of solid dispersions of piroxicam in polyvinylpyrrolidone. International Journal of Pharmaceutics 181: 143-151.

Walking, W.D. (1994). Povidone. In: Wade A, Weller PJ, Ed. Handbook of Pharmaceutical Excipients. Washington DC/London: American Pharmaceutical Association/the Pharmaceutical Press: 392-399. 